\title{
Liver haematoma in pregnancy: A rare complication of HELLP syndrome \\ Pandey C, ${ }^{1}$ Shrestha $\mathrm{J}^{2}{ }^{\mathrm{iD}}$ Timilsina B, ${ }^{\mathrm{iD}}$ Bhattarai $\mathrm{P},{ }^{4}{ }^{\mathrm{iD}}$ Rana $\mathrm{A}^{5}$ iD
}

${ }^{1}$ Chandani Pandey, Postgraduate Resident, ${ }^{2}$ Junu Shrestha, Associate Professor; Department of Obstetrics and Gynaecology; ${ }^{3}$ Bishwodeep Timilsina, Lecturer, Department of Surgery; ${ }^{4}$ Prerana Bhattarai, Postgraduate Resident, Department of Obstetrics and Gynaecology; ${ }^{5}$ Apriharya Rana, MBBS Intern, Manipal College of Medical Sciences, Pokhara, Kaski, Nepal.

\begin{abstract}
Liver haematoma complicating pregnancy with HELLP syndrome is a rare but life-threatening condition. Diagnosis requires a high index of suspicion. Here a case of liver haematoma is presented in a 29 years multigravida at 34 weeks of pregnancy. Initially hypertension was not revealed since she had presented in shock. She had presented with on and off epigastric pain for many days. In context of haemoperitoneum in ultrasound, emergency laparotomy was done and liver haematoma diagnosed intraoperatively. Haematoma was managed with packing and second look laparotomy was done to remove the packs. Haematoma gradually resolved over period of months.
\end{abstract}

Key words: Haematoma; HELLP syndrome; Liver; Pregnancy.

\section{INTRODUCTION}

T TELP syndrome that denotes for Haemolysis, Elevated Liver enzyme and Low platelet, was first described by Weinstein in $1982 .^{1}$ It is associated with severe pre-eclampsia or eclampsia but can occur even in absence of these. The exact aetiology of HELLP syndrome is not known. ${ }^{2}$ Spontaneous liver haematoma is very rare but life-threatening complication of preeclampsia and HELLP syndrome. ${ }^{1}$ Until now only one case has been reported in Nepal. ${ }^{3}$ Here presenting a case

\section{Access this article online}

Website: www.jkmc.com.np

DOI: https://doi.org/10.3126/jkmc.v10i2.40071

HOW TO CITE

Pandey C, Shrestha J, Timilsina B, Bhattarai P, Rana A. Liver haematoma in pregnancy: A rare complication of HELLP syndrome. J Kathmandu Med Coll. 2021;10(2):101-3.

Address for correspondence

Dr. Chandani Pandey

Postgraduate Resident

Department of Obstetrics and Gynaecology

Manipal College of Medical Sciences,

Pokhara, Kaski, Nepal

E-mail: pandeychandani321@gmail.com

Copyright $\odot 2021$ Journal of Kathmandu Medical College (JKMC)

ISSN: 2019-1785 (Print), 2091-1793 (Online)

(7) (8) This work is licensed under a Creative Commons Attribution-Non Commercial 4.0 International License. of 29-year old multiparous woman in third trimester with liver haematoma due to rarity of the case.

\section{CASE REPORT}

A 29-year Gravida 4 Para 3 at 34 weeks of pregnancy presented in emergency department with epigastric pain for one day, which was of sudden onset, progressive, continuous radiating to shoulder tip. She had not perceived foetal movement for past few days. She was booked at local health post near her home. Her antenatal period had been uneventful. However, she had similar pain at the epigastric region three days back. She had been evaluated then: blood pressure was normal, and system and obstetric examination had been normal. Ultrasound of abdomen and obstetric scan were normal. She was prescribed $\mathrm{H} 2$ blockers and antacid and discharged from the emergency department.

On examination, general condition was poor but she was conscious. She was pale and was in shock (pulse was 140 per minute and feeble and Blood Pressure (BP) was 80/?). On Per Abdomen examination, abdomen was soft, guarding and rigidity were absent, uterus corresponded to was 30 to 32 weeks, presentation was cephalic, and uterine contour was maintained. There was no uterine tenderness or contraction. However, mild tenderness was noted over right hypochondrium. Foetal heart was absent. On per vaginal examination cervix was soft, posterior, cervical os was parous with head at -2 station. 
Two large bore cannula were used to open intravenous access. Blood sample was taken and sent for routine tests and blood was arranged and cross-matched. She was resuscitated with intravenous fluid. She was taken for quick scan of abdomen which showed on massive haemoperitoneum with intrauterine foetal death (IUFD) and there was heterogeneous texture of liver.

Her haemoglobin was $7.5 \mathrm{gm} \%$, platelet count was 84,000/cumm, blood urea was $30 \mathrm{mg} / \mathrm{dl}$, creatinine 1.3 $\mathrm{mg} / \mathrm{dl}$. Liver function test showed Alanine Transaminase (ALT) raised by more than 50 folds (2140U/L) and Aspartate Transaminase (AST) raised by more than 30 folds (1240U/L). Lactate dehydrogenase (LDH) was more than four-fold raised (2000U/L).

Emergency exploratory laparotomy was planned and proceeded. There was haemoperitoneum of more than $2000 \mathrm{ml}$. Uterus was intact. Lower segment caesarean section was done and a dead male foetus weighing 2000 grams was delivered. There was no retroplacental clots. On exploration, liver was found to be congested, tense blackish, and ischemic over VI, VII, and VIII segments. Laceration was noted at $\mathrm{V}$ and $\mathrm{VI}$ segments of liver (Figure 1). Haemostatis was tried and eventually, damage control surgery was opted for. Packs were kept over the haematoma to maintain pressure. Intravenous tranxenemic acid was given. Patient was monitored in the intensive care unit and was kept on mechanical ventilation. Fresh blood, platelet rich plasma (PRP), and fresh frozen plasma (FFP) were transfused. Contrast enhanced Computed Tomography (CT) Scan of abdomen was done on second day which showed $8 \mathrm{~cm} \times 7.5 \mathrm{~cm}$ intraparenchymal haematoma on segment VII with subcapsular extension $6 \mathrm{~cm}$ (subcapsular haematoma) and multiple areas of infarction in right lobe of liver.

After 48 hours, second look surgery was done and packs were removed. No active bleeding was noted and abdomen was closed after maintaining haemostasis. Fresh blood, PRP and FFP was transfused as required. Patient was extubated on fifth post-operative day. She was managed with broad-spectrum antibiotics, blood and blood products. However, a rise in BP was noted up to $150 / 100 \mathrm{mmHg}$ noted from fifth post-operative day onwards, which settled over next few days. Gradual improvement was noted over a period of days. There was also gradual improvement in the liver function tests. She was discharged on the $14^{\text {th }}$ post-operative day.

She was regularly followed up over period of months. Serial ultrasound abdomen showed complete resolution of liver with no residual haematoma by three months.
Contrast enhanced CT abdomen and angiography of liver done after one year revealed to be normal and no pathology was diagnosed.

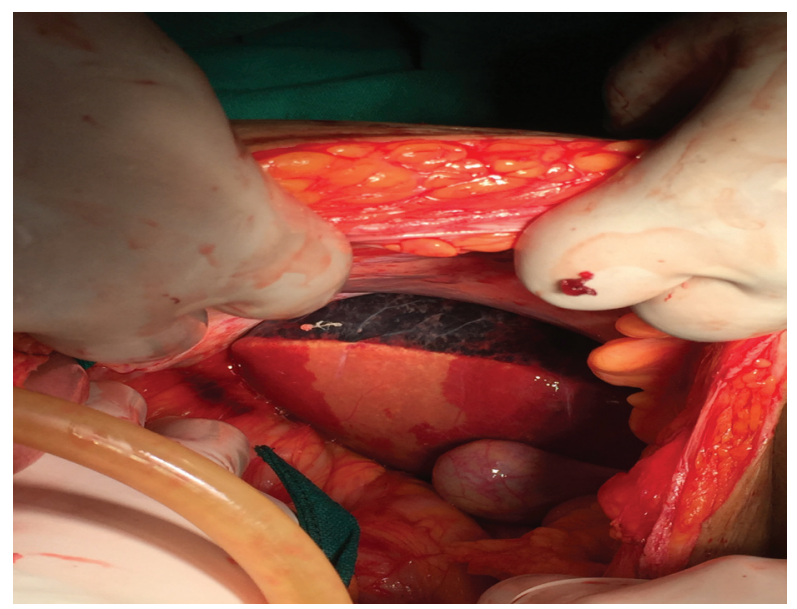

Figure 1: Congested liver with subcapsular haematoma

\section{DISCUSSION}

Liver haematoma is a rare but very fatal condition seen in pregnancy. About $0.39 \%$ to $1.6 \%$ of cases of HELLP syndrome are complicated by liver haematoma. ${ }^{2}$ The incidence of liver haematoma is 1 in 40,000 to 2,50000 deliveries. ${ }^{2}$ It is rather considered as disease of older and multiparous women. ${ }^{4}$ The exact cause is not completely known however the proposed cause mentioned in different literature is basically fibrin deposition in periportal area leading to hepatocytes necrosis and parenchymal haematoma and haemorrhage if there is break in Glisson's capsule. It could also be due to rupture of intraparenchymal vasculature due to mechanical trauma and exacerbated by existing hypertension.,6

When haematoma develops without typical features of pre-eclampsia or HELLP syndrome, it is difficult to differentiate whether the deranged laboratory parameters are because of atypical preeclampsia or HELLP syndrome or due to large haematoma with massive blood loss. However, in this case, rise in the blood pressure later in the post-operative period explained this as a case of HELLP syndrome complicated with liver haematoma.

The clinical presentation may be biphasic consisting of a prodromal phase which can last up to a month with vague symptoms such as epigastric pain, headache, malaise, nausea, vomiting, and jaundice followed by acute phase which is actual rupture phase manifesting as cardiovascular collapse and even death. ${ }^{6}$ This was the presentation of this case as well. 
Liver haematoma is generally misdiagnosed and is diagnosed mostly during laparotomy because of nonspecific symptoms and its rarity. The main diagnostic tool is of liver imaging but decision on modalities of imaging depends on the patient condition. If the patient is haemodynamically unstable, ultrasound will be good for screening as in this case. However, CT scan and Magnetic Resonance Imaging have better sensitivity for the diagnosis of liver haematoma ${ }^{1}$ as done later in this case.

Treatment depends on the haemodynamic status of the patient, size, and state of haematoma. Ruptured haematoma is managed by laparotomy along with temporary intra-abdominal packing with surgical sponges and removal after 48-72 hours as was done in this case. Other options could be application of suture, fibrin glue, absorbable polygalalctin mesh, packing with omentum or rectus sheath, and hepatic artery ligation. ${ }^{1,6}$

\section{REFERENCES}

1. Fan $H$, Zhang $P$, Yang D, Sun L, Zhao W, Pan D, et al. HELLP syndrome complicated by subcapsular liver hematoma: A case report. Med Case Rep Study Protoc. 2020;1:2:e0020. [Full Text | DOI]

2. Han GH, Kim MA. Recurrent spontaneous hepatic rupture in pregnancy: A case report. Medicine (Baltimore). 2018 Jul;97(29):e11458. [PubMed | Full Text | DOI]

3. Shakya VC, Regmi MC, Sah P, Khaniya S, Adhikary S. An alarming but self-limited case of isolated large spontaneous liver hematoma in pregnancy. Pan Afr Med J. 2013;14:36. [PubMed | Full Text | DOI]

4. Cernea D, Dragoescu A, Novac M. HELLP syndrome complicated with postpartum subcapsular ruptured
Recurrence rate and pregnancy outcome after a liver haematoma in subsequent pregnancy is still lacking. Monitoring of early signs of pre-eclampsia and HELLP syndrome and prophylactic low dose aspirin in patients with the previous history can be done. ${ }^{5}$

\section{CONCLUSION}

Liver haematoma, although rare, is a life-threatening condition in pregnancy, mostly a complication of HELLP syndrome. As symptoms are nonspecific, there is a high chance of misdiagnosis. High index of suspicion and appropriate evaluation with imaging modalities make diagnosis possible. Epigastric pain especially in late pregnancy could be initial prodromal symptom of liver haematoma and should never be disregarded in any case.

Conflict of interest: None

Source(s) of support: None liver hematoma and purtscher-like retinopathy. Case Rep Obstet Gynecol. 2012;2012:856135. [PubMed | Full Text | DOI]

5. Ditisheim A, Sibai BM. Diagnosis and management of HELLP syndrome complicated by liver hematoma. Clin Obstet Gynecol. 2017 Mar;60(1):190-7. [PubMed | Full Text | DOI]

6. Singh P, Warren K, Collier V. Ruptured subcapsular liver hematoma: A rare complication of HELLP syndrome. Case Reports Hepatol. 2020 Sep 16;2020:8836329. [PubMed | Full Text | DOI]

7. Ghorbanpour M, Makarchian HR, Yousefi B, Taghipour M. Conservative management of postpartum HELLP syndrome and intraparenchymal liver hematoma: A case report. Bull Emerg Trauma. 2019 Apr;7(2):196-8. [PubMed | Full Text | DOI] 